\title{
Peroxidised dietary lipids impair intestinal function and morphology of the small intestine villi of nursery pigs in a dose-dependent manner
}

\author{
David S. Rosero ${ }^{1,2}$, Jack Odle ${ }^{1}$, Adam J. Moeser ${ }^{3}$, R. Dean Boyd ${ }^{1,2}$ and Eric van Heugten ${ }^{1 *}$ \\ ${ }^{1}$ Department of Animal Science, North Carolina State University, Raleigh, NC 27695, USA \\ ${ }^{2}$ Hanor Company LLC, Franklin, KY 42134, USA \\ ${ }^{3}$ Department of Large Animal Clinical Sciences, Michigan State University, East Lansing, MI 48824, USA \\ (Submitted 5 May 2015 - Final revision received 1 September 2015 - Accepted 2 September 2015 - First published online 6 October 2015)
}

\section{Abstract}

The objective of this study was to investigate the effect of increasing degrees of lipid peroxidation on structure and function of the small intestine of nursery pigs. A total of 216 pigs (mean body weight was $6.5 \mathrm{~kg}$ ) were randomly allotted within weight blocks and sex and fed one of five experimental diets for $35 \mathrm{~d}$ (eleven pens per treatment with three to four pigs per pen). Treatments included a control diet without added lipid, and diets supplemented with $6 \%$ soyabean oil that was exposed to heat $\left(80^{\circ} \mathrm{C}\right)$ and constant oxygen flow $(1$ litre/min) for $0,6,9$ and $12 \mathrm{~d}$. Increasing lipid peroxidation linearly reduced feed intake $(P<0.001)$ and weight gain $(P=0.024)$. Apparent faecal digestibility of gross energy $(P=0.001)$ and fat $(P<0.001)$ decreased linearly as the degree of peroxidation increased. Absorption of mannitol (linear, $P=0.097$ ) and $\mathrm{D}$-xylose (linear, $P=0.089$ ), measured in serum $2 \mathrm{~h}$ post gavage with a solution containing $0.2 \mathrm{~g} / \mathrm{ml} \mathrm{of} \mathrm{D-xylose} \mathrm{and} 0.3 \mathrm{~g} / \mathrm{ml}$ of mannitol, tended to decrease progressively as the peroxidation level increased. Increasing peroxidation also resulted in increased villi height (linear, $P<0.001$ ) and crypt depth (quadratic, $P=0.005$ ) in the jejunum. Increasing peroxidation increased malondialdehyde concentrations (quadratic, $P=0.035$ ) and reduced the total antioxidant capacity (linear, $P=0.044$ ) in the jejunal mucosa. In conclusion, lipid peroxidation progressively diminished animal performance and modified the function and morphology of the small intestine of nursery pigs. Detrimental effects were related with the disruption of redox environment of the intestinal mucosa.

\section{Key words: Lipid peroxidation: Oxidative stress: Pigs: Small intestine}

Dietary peroxidised lipids are of nutritional relevance because their intake has been linked to gastrointestinal disorders ${ }^{(1-3)}$. Contribution of peroxidised lipids to human diets has markedly increased because of the elevated consumption of processed lipids and increased use of unsaturated oils in the cooking processes. Frying oils are heated to temperatures that range from 177 to $195^{\circ} \mathrm{C}$ for extended periods of time (up to $8 \mathrm{~h}$ for more than 1 week $)^{(4)}$. Under such conditions, lipids become increasingly peroxidised, resulting in a large number of unstable and toxic compounds (hydroperoxides, aldehydes, alcohols, conjugated dienes, polymers and so on $)^{(4)}$. In a recent study, Sebastian et al. ${ }^{(5)}$ determined that 'in-use' frying oils from $80 \%$ of the tested restaurants $(n$ 20) in Canada were highly peroxidised (peroxide values up to $48 \mathrm{mEq} \mathrm{O} 2 / \mathrm{kg}$ and $p$-anisidine values (relative measurement of aldehydes content) up to 41). The degree of peroxidation of 'discarded lipids' was even greater (peroxide values up to $248 \mathrm{mEq} \mathrm{O} \mathrm{O}_{2} / \mathrm{kg}$ and $p$-anisidine values up to 57 ). This is a great concern not only for human nutrition, as the content of peroxidised lipids in fried products (i.e. fried potatoes, tortilla chips and so on) may be up to $38 \%{ }^{(5)}$, but also for animal nutrition because discarded lipids are commonly recycled into livestock diets.
Understanding the effects of lipid peroxidation in the small intestine is particularly important because intestinal epithelial cells experience greater exposure to lipid peroxidation products. Early research provided evidence of the toxicity of peroxidised lipid products ${ }^{(6,7)}$ and cautioned their use in livestock feeds because this could result in a reduction of productivity ${ }^{(8,9)}$. Recent studies investigated the deleterious effects of hydroperoxides, aldehydes and other lipid peroxidation subproducts on intestinal cell lines ${ }^{(2,10)}$ and animals ${ }^{(7,11,12)}$. Dietary peroxidised lipids can induce oxidative stress and impair the antioxidant defence system ${ }^{(11,13)}$. In the small intestine, oxidative stress and disruption of cellular redox status by peroxidised lipids increase cellular transition responses (proliferative, growth arrest and apoptosis $)^{(10,14)}$, disrupting intestinal turnover and cell survival. Moreover, there is evidence that induction of oxidative stress and disruption of redox balance in intestinal cells contributes to a loss of intestinal integrity and activates proinflammatory transcription factors ${ }^{(2)}$. Despite the recognition of lipid peroxidation as modulator of gastrointestinal disorders, little is known regarding the effects of lipid peroxidation on the structure and function of the small intestine.

Abbreviations: BW, body weight; MDA, malondialdehyde.

* Corresponding author: E. van Heugten, fax +1919 515 6884, email Eric_vanHeugten@ncsu.edu 
Although the deleterious effects of lipid peroxidation are of biological relevance, experiments conducted using animal models have produced conflicting results. For instance, Varady et $a l^{(12)}$ determined that lipid peroxidation activated inflammatory transcription factors in mice, whereas Ringseis et al. ${ }^{(11)}$ did not observe inflammatory responses in pigs fed peroxidised lipids. Recently, Liu et al. ${ }^{(15)}$ concluded that supplementation of $10 \%$ peroxidised lipids to diets of young pigs did not affect intestinal integrity. Inconsistencies, when using animal models, may be because of differences in the methodology used, especially in regard to the extent of lipid peroxidation. Researchers have suggested that there is a minimum threshold for lipid peroxidation above which detrimental effects are noticeable ${ }^{(8,16)}$. However, there are very few studies that investigated the biological responses to increasing degrees of lipid peroxidation, and it is unknown whether lipid peroxidation will exert gradual detrimental effects. Therefore, in the present study, we investigated the effects of increasing degrees of lipid peroxidation on growth response, intestinal morphology and function of the small intestine in young pigs.

\section{Methods}

All animal care and use procedures for the present experiment were approved by the Institutional Animal Care and Use Committee of North Carolina State University.

\section{Experimental design and dietary treatments}

A total of 216 crossbred barrows and gilts $(6.5 \mathrm{~kg}$ body weight (BW)), weaned between 19 and $21 \mathrm{~d}$ of age, were randomly allotted within weight blocks and sex to fifty-five standard nursery pens (three to four pigs per pen). Weaned pigs were fed a phase 1 nursery diet for $14 \mathrm{~d}$, followed by a phase 2 diet for $21 \mathrm{~d}$ (Table 1). Dietary treatments in each of the phases included a negative control diet (no added soyabean oil), and diets supplemented with $6 \%$ soyabean oil previously exposed to peroxidation conditions (described below) for 0, 6, 9 and $12 \mathrm{~d}$. Diets supplemented with peroxidised soyabean oil were manufactured from a common basal mix and formulated to a constant nutrient: metabolisable energy ratio. Titanium dioxide was included in all diets as an indigestible marker for the determination of fat and gross energy digestibility. All nutrients exceeded the nutrient requirements suggested by the $\mathrm{NRC}^{(17)}$. Pigs were offered free access to water. Feed was available ad libitum, with precaution taken to avoid feed wastage. All diets were offered in meal form. Body and feeder weights were recorded on d 0, 14 and 35 for computation of growth performance.

\section{Peroxidation and chemical analysis of soyabean oil}

Pure soyabean oil $(60 \mathrm{~kg})$ was placed into polyethylene drums equipped with immersion heaters. Soyabean oil was exposed to peroxidation by heating at $80^{\circ} \mathrm{C}$ while bubbling oxygen gas through the oil at a constant rate of 1 litre $/ \mathrm{min}$. After peroxidative exposure for $0,6,9$ and $12 \mathrm{~d}$, soyabean oil was stabilised with $0.5 \mathrm{~g}$ of an antioxidant (Rendox AT 20
Table 1. Ingredient and chemical composition of the experimental diets on an as-fed basis

\begin{tabular}{|c|c|c|c|c|}
\hline \multirow[b]{2}{*}{ Items } & \multicolumn{2}{|c|}{ Phase I } & \multicolumn{2}{|c|}{ Phase II } \\
\hline & Control & Oil added & Control & Oil added \\
\hline \multicolumn{5}{|l|}{ Ingredients (g/kg) } \\
\hline Yellow maize & $435 \cdot 2$ & 331.8 & $683 \cdot 7$ & $585 \cdot 6$ \\
\hline Soyabean meal & $194 \cdot 2$ & $237 \cdot 0$ & $275 \cdot 3$ & $312 \cdot 8$ \\
\hline Lactose & $150 \cdot 0$ & $150 \cdot 0$ & - & - \\
\hline Dried whey & $100 \cdot 0$ & $100 \cdot 0$ & - & - \\
\hline Fishmeal & $50 \cdot 0$ & $50 \cdot 0$ & - & - \\
\hline Plasma protein & $40 \cdot 0$ & $40 \cdot 0$ & - & - \\
\hline L-Lys $\mathrm{HCl}$ & $2 \cdot 3$ & 2.4 & $3 \cdot 3$ & 3.6 \\
\hline DL-Met & 1.4 & 1.9 & $1 \cdot 1$ & 1.5 \\
\hline L-Thr & 0.8 & $1 \cdot 1$ & $1 \cdot 1$ & $1 \cdot 3$ \\
\hline Soyabean oil ${ }^{*}$ & - & $60 \cdot 0$ & - & $60 \cdot 0$ \\
\hline Monocalcium phosphate & 8.8 & 8.7 & $14 \cdot 2$ & $14 \cdot 1$ \\
\hline Ground limestone & $6 \cdot 0$ & 5.8 & $10 \cdot 4$ & $10 \cdot 2$ \\
\hline Zinc oxide & 2.5 & 2.5 & $4 \cdot 0$ & $4 \cdot 0$ \\
\hline Copper sulphate & 0.8 & 0.8 & - & - \\
\hline Salt & $1 \cdot 0$ & 1.0 & - & - \\
\hline Mineral premix $†$ & 1.5 & 1.5 & 1.5 & 1.5 \\
\hline Vitamin premix $\ddagger$ & 0.5 & 0.5 & 0.4 & 0.4 \\
\hline Titanium dioxide§ & $5 \cdot 0$ & $5 \cdot 0$ & $5 \cdot 0$ & $5 \cdot 0$ \\
\hline \multicolumn{5}{|l|}{ Calculated composition ( $\mathrm{g} / \mathrm{kg}$ ) } \\
\hline Crude protein & $207 \cdot 0$ & $219 \cdot 0$ & $192 \cdot 0$ & $202 \cdot 0$ \\
\hline Crude fat & $29 \cdot 0$ & $86 \cdot 0$ & $35 \cdot 0$ & $92 \cdot 0$ \\
\hline SID Lys & $13 \cdot 5$ & $14 \cdot 6$ & 11.5 & $12 \cdot 5$ \\
\hline SID Thr & $8 \cdot 4$ & $9 \cdot 1$ & $7 \cdot 1$ & $7 \cdot 7$ \\
\hline $\mathrm{Ca}$ & $8 \cdot 0$ & $8 \cdot 0$ & $7 \cdot 5$ & $7 \cdot 5$ \\
\hline Total P & $7 \cdot 3$ & $7 \cdot 2$ & $6 \cdot 8$ & $6 \cdot 8$ \\
\hline Available $\mathrm{P}$ & $5 \cdot 0$ & $5 \cdot 0$ & $3 \cdot 7$ & $3 \cdot 7$ \\
\hline $\mathrm{ME}(\mathrm{MJ} / \mathrm{kg})$ & $13 \cdot 8$ & $15 \cdot 1$ & $13 \cdot 8$ & $15 \cdot 1$ \\
\hline
\end{tabular}

SID, standard ileal digestibility; ME, metabolisable energy.

* Soyabean oil was exposed to peroxidation for 0, 6, 9 and $12 \mathrm{~d}$.

† Supplied per kg of complete diet (mg): ferrous sulphate, 550; zinc oxide, 230; manganese sulphate, 133; copper sulphate, 65; ethylene diamine dihydriodide, 0.38 ; sodium selenite, 0.66

‡ Supplied per kg of complete diet $(\mathrm{mg})$ : retinol, 2.5; cholecalciferol, 0.029; DL-a-tocopherol, 31.5; vitamin $\mathrm{B}_{12}, 0.03$; riboflavin, 5.8; calcium pantothenate, 23.5; niacin, 35.2; menadione dimethylpyrimidinol bisulphate, 3.8; folic acid, 1.7; and biotin, 0.23 .

$\S$ Used as an indigestible marker for determination of dietary fat and gross energy digestibility.

Liquid; Kemin Industries) and stored under refrigeration $\left(4^{\circ} \mathrm{C}\right)$ to prevent further peroxidation.

The chemical composition and peroxidation measures of the soyabean oil (Table 2) were determined in representative samples by a commercial laboratory (New Jersey Feed Laboratory Inc.) according to standard procedures of AOAC ${ }^{(18)}$ and American Oil Chemists' Society ${ }^{(19)}$. Amounts of hydroperoxides in soyabean oil were estimated by measuring the initial peroxide value. The $p$-anisidine value is a relative measurement and was used to determine the aldehyde content of peroxidised oils. Concentrations of malondialdehyde (MDA, used as an index of lipid peroxidation) in samples were analysed using a commercial ELISA kit (Cell Biolabs). All analyses were conducted in duplicate, and intra- and inter-assay CV were $<5 \%$.

\section{Nutrient digestibility}

Faecal samples from eight pens per dietary treatment were collected from at least two pigs in each pen from d 11 to 14 and from d 32 to 35 . Samples were then pooled within the pen and within the collection period and dried at $60^{\circ} \mathrm{C}$ in a forced-air 
Table 2. Chemical composition and peroxidation analysis of the soyabean oil used in the dietary treatments

\begin{tabular}{|c|c|c|c|c|}
\hline \multirow[b]{2}{*}{ Items } & \multicolumn{4}{|c|}{ Days of peroxidative exposure* } \\
\hline & 0 & 6 & 9 & 12 \\
\hline \multicolumn{5}{|l|}{ Fatty acids $(\%) \dagger$} \\
\hline $16: 0$ & 10.5 & $10 \cdot 5$ & $10 \cdot 7$ & $10 \cdot 6$ \\
\hline $18: 0$ & 4.7 & 4.7 & 4.7 & 4.7 \\
\hline $18: 1 n-9$ & 21.9 & $22 \cdot 0$ & $22 \cdot 1$ & $22 \cdot 3$ \\
\hline $18: 1 n-7$ & 1.5 & 1.8 & 1.6 & 1.6 \\
\hline $18: 2 n-6$ & 53.1 & 53.0 & 52.5 & 52.5 \\
\hline $18: 3 n-3$ & 6.9 & 6.9 & 6.7 & $6 \cdot 7$ \\
\hline Other fatty acids $\ddagger$ & 1.4 & 1.2 & 1.8 & 1.5 \\
\hline Total fatty acids & 98.8 & 98.6 & $98 \cdot 2$ & $97 \cdot 1$ \\
\hline \multicolumn{5}{|l|}{ Chemical analysis (\%) } \\
\hline Free fatty acids & 0.1 & 0.1 & 0.1 & 0.1 \\
\hline Moisture & 0.0 & 0.0 & 0.4 & 0.2 \\
\hline Insoluble impurities & 0.0 & 0.0 & 0.0 & 0.0 \\
\hline Unsaponifiable matter & 0.7 & 0.7 & 0.6 & 0.6 \\
\hline \multicolumn{5}{|l|}{ Peroxidation parameters } \\
\hline$p$-Anisidine value§ & 4.0 & $19 \cdot 0$ & $25 \cdot 0$ & $39 \cdot 0$ \\
\hline MDA (mmol// oil) & 1.1 & 4.5 & 5.6 & 6.9 \\
\hline \multicolumn{5}{|c|}{ Peroxide value $\left(\mathrm{mEq} \mathrm{O}_{2} / \mathrm{kg}\right)$} \\
\hline Initial AOM & 1.0 & $46 \cdot 0$ & 58.0 & $52 \cdot 0$ \\
\hline $4 \mathrm{~h} \mathrm{AOM}$ & 11.0 & $90 \cdot 0$ & 94.0 & 84.0 \\
\hline $24 \mathrm{~h} \mathrm{AOM}$ & 409.0 & 568.0 & 508.0 & $517 \cdot 0$ \\
\hline
\end{tabular}

MDA, malondialdehyde; AOM, active oxygen method.

* Soyabean oil was exposed to peroxidation for $0,6,9$ and $12 \mathrm{~d}$ by exposing to heat $\left(80^{\circ} \mathrm{C}\right)$ and constant oxygen flow ( 1 litre/min).

$\dagger$ Weight percentage of total fatty acids.

$\ddagger$ Comprised $<1 \%$ of each of the following fatty acids: $14: 0,16: 1,17: 0,20: 0,20: 1$ and $22: 0$.

$\S$ The $p$-anisidine value is a relative measurement used to determine the aldehydes content of peroxidised oils.

oven for $48 \mathrm{~h}$. After drying, the samples were finely ground in a Wiley mill (Thomas Scientific) through a $0 \cdot 8-\mathrm{mm}$ mesh screen and mixed. Contents of titanium dioxide in feed and faecal samples were determined according to the protocol described by Myers et $a{ }^{(20)}$. Total fat in samples was determined after acid hydrolysis $\left(3 \mathrm{~mol} / \mathrm{l}\right.$ for $1 \mathrm{~h}$ at $90^{\circ} \mathrm{C}$ ) according to American Oil Chemists' Society ${ }^{(21)}$ for rapid determination of fat using high-temperature solvent extraction with the use of specialised equipment (XT15; Ankom). Gross energy content of samples was determined using a bomb calorimeter (C5000; IKA Works). The apparent faecal digestibility of fat and gross energy was calculated using the index method, as described by Adeola ${ }^{(22)}$.

\section{Intestinal absorptive capacity}

A procedure adapted from Doerfler et al. ${ }^{(23)}$ was used to measure the intestinal absorptive capacity. At d 14 of the study and before pigs were switched to phase 2 diets, eight pigs per dietary treatment (one pig with average $\mathrm{BW}$ in each pen) were selected. Pigs were deprived of feed for $9 \mathrm{~h}$ and then gavaged with a solution containing $0.2 \mathrm{~g} / \mathrm{ml}$ of D-xylose and $0.3 \mathrm{~g} / \mathrm{ml}$ of mannitol (Sigma-Aldrich). Pigs received a dose of $6.5 \mathrm{ml}$ of solution per $\mathrm{kg}$ of $\mathrm{BW}$. Pigs were bled $2 \mathrm{~h}$ after gavage via jugular venepuncture using a vacuum tube with a $20 \mathrm{G} \times$ $3.81 \mathrm{~cm}$ needle. This procedure was repeated on $\mathrm{d} 35$ using the same selected pigs.

Serum samples were frozen at $-20^{\circ} \mathrm{C}$ until analysis was conducted. For analysis, samples were spiked with fucose solution (Sigma-Aldrich), which served as an internal standard for calculation. Samples were then diluted 100-fold with deionised water. Diluted samples were filtered through OnGuard-H cartridges (Dionex) to remove free amino acids. HPLC analysis was performed according to the method of Jahnel et $a l .{ }^{(24)}$. The HPLC system (Dionex) consisted of a $250 \times 4 \mathrm{~mm}$ Dionex PA-1 column, a gradient pump, an autosampler and a pulsed amperometric detector. The quantification was performed by calculating the ratio of the unknown peak height:fucose peak height.

\section{Tissue and mucosal sample collection}

At d 35 of the study, seven pigs per treatment (different from pigs used in the absorptive capacity test) were randomly selected and euthanised by captive bolt gun followed by immediate exsanguination. Tissue samples were collected from the proximal jejunum, the main site of digestion and absorption of lipids, and used for analysis of intestinal histology. Mucosal scrapings from the proximal jejunum were collected and frozen immediately in liquid $\mathrm{N}_{2}$. Samples were stored under $-80^{\circ} \mathrm{C}$ until biochemical analyses were undertaken.

\section{Histological measurements}

Collected tissue samples were fixed in $10 \%$ neutral-buffered formalin, transferred to $70 \%$ ethanol after $24 \mathrm{~h}$, embedded in paraffin, sectioned $(5 \mu \mathrm{m})$ and stained with haematoxylin-eosin. Slides were read using an Olympus Vanox-S microscope and analysed using SPOT Basic Imaging software (Diagnostic Instruments). Measurements of villus height and width and crypt depth were performed as previously described by Moeser $e t a l{ }^{(25)}$. The surface area of the villus was calculated using the formula for the surface area of a cylinder and subtracting the area of the base of the villus.

\section{Mucosal sample analyses}

Oxidative stress in jejunum mucosa was assessed by measuring concentrations of MDA. Collected samples were homogenised in PBS containing butylated hydroxytoluene to prevent further oxidation. Supernatants were collected and analysed for MDA concentrations using a commercial ELISA kit according to the manufacturer's protocol. Concentrations of MDA in samples were expressed as $\mu$ mol per $g$ of mucosal protein. Total antioxidant capacity (TAC) was used as an estimation of the collective capacity of biomolecules in mucosal samples to exert antioxidant activity. To assess TAC, mucosal samples were homogenised in cold PBS. Supernatants were collected and analysed by using a commercial ELISA kit. Results were expressed as $\mu \mathrm{mol} \mathrm{Cu}$-reducing equivalents per $\mathrm{g}$ of mucosal protein. Mucosal protein was measured using a commercial ELISA kit (Thermo Scientific). To determine the concentrations of TNF in jejunum mucosa, samples were homogenised in cold PBS and the supernatant was collected and analysed using a commercial ELISA kit (R\&D Systems). Results were expressed as pg per mg of mucosal protein. 


\section{Statistical analysis}

Animal performance data were analysed as a randomised complete block design using the MIXED procedure of SAS statistical package (version 9.3; SAS Institute Inc.). The fitted model included dietary treatment and sex and their interaction as the fixed effects and weight blocks as random effect. Intestinal absorptive capacity and nutrient digestibility data were assessed at d 14 and 35 of the study and analysed using the MIXED procedure of SAS with repeated measures. Data for intestinal histology, metabolic oxidative stress, antioxidant activity and cytokine analysis corresponded to a complete randomised design and were analysed using the general linear model procedure of SAS. Pen was considered the experimental unit for the analysis of animal performance and nutrient digestibility data, whereas individual pig was considered as the experimental unit for other measurements. The main effect of lipid peroxidation was tested. Df were partitioned into orthogonal contrasts to evaluate linear and quadratic effects of lipid peroxidation. All data were expressed as least square means with their standard errors. $P$ values $\leq 0.05$ were considered to be statistically significant, and values $>0.05$ but $<0.10$ were considered as tendencies towards differences.

\section{Results}

\section{Peroxidation analysis of soyabean oil}

As shown in Table 2, analysis of the soyabean oil indicated that peroxidative exposure for increasing lengths of time resulted in increasing $p$-anisidine values and MDA concentrations.
Initial peroxide value of soyabean oil increased until d 9 and remained relatively similar on $\mathrm{d} 12$. Contrary to these observations, exposure to peroxidation did not affect moisture, free fatty acids, insoluble impurities or unsaponifiable matter of soyabean oil.

\section{Growth performance}

For the entire period of the study ( $\mathrm{d} 0-35$ ), nursery pigs fed diets supplemented with soyabean oil ( $0 \mathrm{~d}$ of peroxidation) grew faster $(P=0.027)$ and displayed improved feed efficiency $(P=0.006)$ when compared with those fed the negative control diet without soyabean oil (Table 3 ). In addition, feed intake (linear, $P<0 \cdot 001$ ), energy intake (linear, $P<0.001$ ) and weight gain (linear, $P=0.024)$, but not feed efficiency $(P=0.923)$, decreased as the added soyabean oil was increasingly peroxidised. During the first $14 \mathrm{~d}$, increased peroxidation of soyabean oil reduced the feed intake (quadratic, $P<0.001)$, but not weight gain $(P=0.915)$ or feed efficiency $(P=0.990)$, of pigs. For d $15-35$ of the study, detrimental effects of lipid peroxidation observed on animal performance were more evident. Increasing soyabean oil peroxidation linearly reduced feed intake $(P=0.002)$, energy intake $(P=0.002)$ and weight gain $(P=0.016)$, but not the efficiency of feed utilisation $(P=0.374)$ of pigs.

\section{Nutrient digestibility}

During the first $14 \mathrm{~d}$ (Fig. 1(A)) and $35 \mathrm{~d}$ (Fig. 2(B)) of the study, the apparent faecal digestibility of dietary fat and gross energy for nursery pigs fed diets supplemented with soyabean oil ( $0 \mathrm{~d}$ of peroxidation) was much greater than for those fed the

Table 3. Effects of peroxidised dietary soyabean oil on growth performance of nursery pigs

(Least squares means with their standard errors)

\begin{tabular}{|c|c|c|c|c|c|c|c|c|c|c|}
\hline \multirow[b]{2}{*}{ Items } & \multirow[b]{2}{*}{ Control† } & \multicolumn{4}{|c|}{ Days of peroxidative exposure* } & \multirow[b]{2}{*}{ SEM } & \multicolumn{4}{|c|}{$P$} \\
\hline & & 0 & 6 & 9 & 12 & & Control $v$. oil added $\ddagger$ & Peroxidation§ & Linear & Quadratic \\
\hline Initial BW (kg) & 6.5 & 6.5 & 6.5 & 6.5 & 6.5 & $0 \cdot 2$ & 0.990 & 0.998 & 0.787 & 0.894 \\
\hline Final BW (kg) & $20 \cdot 3$ & $21 \cdot 6$ & $20 \cdot 9$ & $20 \cdot 7$ & $20 \cdot 3$ & 0.5 & 0.070 & 0.337 & 0.068 & 0.938 \\
\hline \multicolumn{11}{|l|}{$\mathrm{FI}(\mathrm{g} / \mathrm{d})$} \\
\hline d 0-14 & $354^{a}$ & $334^{c}$ & $351^{a, b}$ & $338^{b, c}$ & $325^{c}$ & 5 & 0.008 & 0.006 & 0.264 & $<0.001$ \\
\hline d 15-35 & $829^{a}$ & $810^{a}$ & $795^{a, b}$ & $769^{\mathrm{b}, \mathrm{c}}$ & $750^{c}$ & 13 & 0.302 & 0.015 & 0.002 & 0.429 \\
\hline d 0-35 & $633^{a}$ & $621^{a}$ & $634^{a}$ & $588^{b}$ & $576^{b}$ & 9 & 0.219 & $<0.001$ & $<0.001$ & 0.010 \\
\hline \multicolumn{11}{|l|}{ El (MJ/d (Mcal/d)) } \\
\hline d 0-14 (MJ/d) & $4 \cdot 9^{\mathrm{b}}$ & $5 \cdot 0^{\mathrm{b}}$ & $5 \cdot 4^{\mathrm{a}}$ & $5 \cdot 1^{\mathrm{b}}$ & $4 \cdot 9^{\mathrm{b}}$ & 0.08 & $1 \cdot 3$ & $<0.001$ & 0.233 & $<0.001$ \\
\hline d 0-14 (Mcal/d) & $1 \cdot 18^{b}$ & $1 \cdot 20^{\mathrm{b}}$ & $1 \cdot 30^{a}$ & $1 \cdot 22^{b}$ & $1 \cdot 17^{\mathrm{b}}$ & 0.02 & 0.303 & $<0.001$ & 0.233 & $<0.001$ \\
\hline d 15-35 (MJ/d) & $11.4^{c}$ & $12 \cdot 1^{\mathrm{a}}$ & $12 \cdot 0^{\mathrm{a}, \mathrm{b}}$ & $11 \cdot 5^{\mathrm{b}, \mathrm{c}}$ & $11 \cdot 3^{\mathrm{C}}$ & 0.2 & 0.025 & 0.015 & 0.002 & 0.370 \\
\hline d 15-35(Mcal/d) & $2 \cdot 72^{\mathrm{C}}$ & $2 \cdot 90^{\mathrm{a}}$ & $2 \cdot 86^{a, b}$ & $2 \cdot 76^{\mathrm{b}, \mathrm{c}}$ & $2 \cdot 69^{c}$ & 0.05 & 0.006 & 0.015 & 0.002 & 0.370 \\
\hline $\mathrm{d} 0-35(\mathrm{MJ} / \mathrm{d})$ & $8 \cdot 8^{\mathrm{b}}$ & $9 \cdot 3^{a}$ & $9 \cdot 4^{\mathrm{a}}$ & $8 \cdot 8^{\mathrm{b}}$ & $8 \cdot 7^{\mathrm{b}}$ & 0.12 & 0.020 & $<0.001$ & $<0.001$ & 0.070 \\
\hline d 0-35 (Mcal/d) & $2 \cdot 11^{b}$ & $2 \cdot 23^{a}$ & $2 \cdot 24^{\mathrm{a}}$ & $2 \cdot 12^{b}$ & $2.08^{b}$ & 0.03 & 0.005 & $<0.001$ & $<0.001$ & 0.070 \\
\hline \multicolumn{11}{|l|}{ BW gain $(g / d)$} \\
\hline d $0-14$ & 253 & 257 & 255 & 262 & 250 & 11 & 0.790 & 0.915 & 0.811 & 0.746 \\
\hline d 15-35 & $484^{b}$ & $538^{a}$ & $504^{a, b}$ & $493^{b}$ & $485^{b}$ & 16 & 0.015 & 0.110 & 0.016 & 0.671 \\
\hline d 0-35 & $393^{b}$ & $431^{a}$ & $408^{a, b}$ & $400^{a, b}$ & $392^{b}$ & 12 & 0.027 & 0.156 & 0.024 & 0.851 \\
\hline \multicolumn{11}{|c|}{ Feed efficiency (gain:feed) } \\
\hline d 0-14 & 0.72 & 0.77 & 0.77 & 0.78 & 0.77 & 0.03 & 0.246 & 0.990 & 0.837 & 1.000 \\
\hline d 15-35 & $0.58^{b}$ & $0.65^{a}$ & $0.63^{a}$ & $0.64^{a}$ & $0.68^{a}$ & 0.02 & 0.003 & 0.374 & 0.485 & 0.105 \\
\hline d 0-35 & $0.61^{\mathrm{b}}$ & $0.68^{a}$ & $0.67^{a}$ & $0.67^{a}$ & $0.68^{a}$ & 0.02 & 0.006 & 0.923 & 0.997 & 0.490 \\
\hline
\end{tabular}

$\mathrm{BW}$, body weight; $\mathrm{FI}$, feed intake; $\mathrm{El}$, metabolisable energy intake.

a,b,c Least squares mean values within a row with unlike superscript letters were significantly different $(P \leq 0.05)$

* Soyabean oil added to diets was exposed to peroxidation for $0,6,9$ and $12 \mathrm{~d}$ by exposing to heat $\left(80^{\circ} \mathrm{C}\right)$ and constant oxygen flow ( 1 litre/min).

$\dagger$ Control diet was not supplemented with soyabean oil.

$\ddagger P$ value corresponding to the comparison of control with $0 \mathrm{~d}$ peroxidised lipid-added diet

$\S$ The main effect of lipid peroxidation was tested. Orthogonal contrasts were performed to evaluate linear and quadratic effects of lipid peroxidation. 
(A)

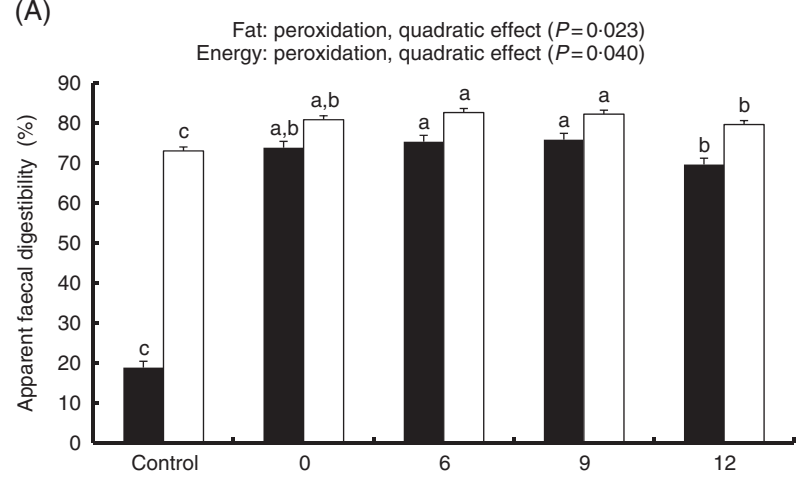

(B)

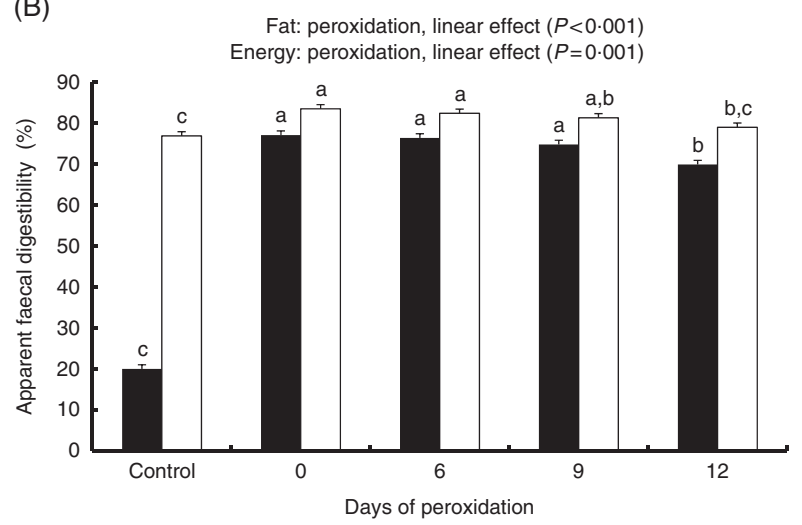

Fig. 1. Apparent faecal digestibility of dietary fat $(\square)$ and gross energy ( $\square$ ) measured during d 11-14 (A) and d 32-35 (B) in nursery pigs fed either a negative control diet without added lipid or diets with $6 \%$ supplemented lipid. Soyabean oil added to diets was exposed to peroxidation for $0,6,9$ and $12 \mathrm{~d}$ by exposing to heat $\left(80^{\circ} \mathrm{C}\right)$ and constant oxygen flow $(1 \mathrm{litre} / \mathrm{min})$. Values are means $(n 8)$, with their standard errors represented by vertical bars. ${ }^{\mathrm{a}, \mathrm{b}, \mathrm{c}}$ Mean values, within outcome variable, lacking an unlike letter were significantly different $(P<0.05)$. The main effect of lipid peroxidation was tested for lipidsupplemented diets. Orthogonal contrasts were performed to evaluate linear and quadratic effects of lipid peroxidation.

negative control diet without soyabean oil $(P<0 \cdot 001)$. During the first $14 \mathrm{~d}$ of the study, apparent faecal digestibility of fat $(P=0.023)$ and gross energy $(P=0.040)$ in nursery pigs decreased in a quadratic manner as the added soyabean oil was increasingly peroxidised. As experimental diets were fed to pigs for longer periods ( $\mathrm{d}$ 15-35), increasing peroxidation linearly reduced apparent faecal digestibility of fat $(P<0.001)$ and gross energy $(P=0 \cdot 001)$.

\section{Intestinal absorptive capacity}

At d 14 of the study, dietary inclusion of peroxidised soyabean oil did not affect the concentrations of mannitol $(P=0.800)$ or D-xylose $(P=0.944)$ measured in blood samples collected from pigs $2 \mathrm{~h}$ after oral administration (Fig. 2(A)). In contrast, concentrations of mannitol (linear, $P=0.097$ ) and $\mathrm{D}$-xylose (linear, $P=0.089)$ in blood samples collected on d 35 tended to decrease as the added soyabean oil was increasingly peroxidised (Fig. 2(B)).

\section{Histological measurements}

Increasing soyabean oil peroxidation resulted in longer (linear, $P<0.001$ ) and thinner (linear, $P=0.002$ ) villi and deeper crypts
(A)
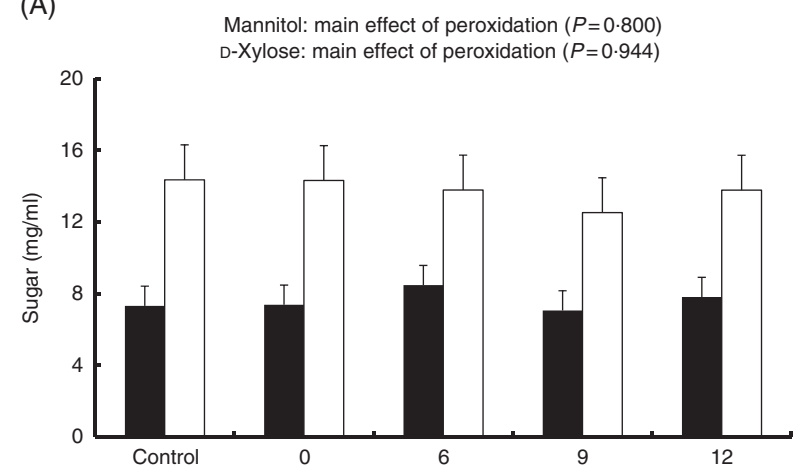

(B)

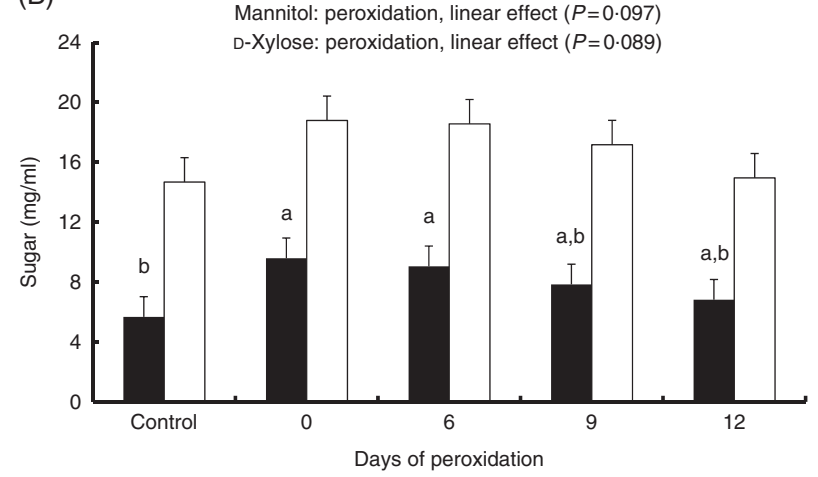

Fig. 2. Intestinal absorptive capacity measured using mannitol ( $\square$ ) and D-xylose ( $\square$ ) on d 14 (A) and d 35 (B) in nursery pigs fed either a negative control diet without added lipid or diets with $6 \%$ supplemented lipid. Soyabean oil added to diets was exposed to peroxidation for $0,6,9$ and $12 \mathrm{~d}$ by exposing to heat $\left(80^{\circ} \mathrm{C}\right)$ and constant oxygen flow (1 litre/min). Values are means $(n 8)$, with their standard errors represented by vertical bars. ${ }^{a, b}$ Mean values, within outcome variable, lacking an unlike letter were significantly different $(P<0.05)$. The main effect of lipid peroxidation was tested for lipid-supplemented diets. Orthogonal contrasts were performed to evaluate linear and quadratic effects of lipid peroxidation.

(quadratic, $P=0.005$ ) in the jejunum (Table 4 ). This resulted in greater villus height:crypt depth ratios, as the added soyabean oil was increasingly peroxidised (quadratic, $P=0.022$ ). Moreover, effects of peroxidised soyabean oil on villus area were not detected $(P=0.851)$.

\section{Mucosal sample analyses}

Increasing soyabean oil peroxidation increased the concentrations of MDA (quadratic, $P=0.035$; Table 4) and reduced the antioxidant capacity in the mucosal samples from the jejunum (linear, $P=0.044$ ). To explore the impact of dietary inclusion of peroxidised soyabean oil on intestinal inflammation, we measured mucosal concentrations of TNF in the jejunum of pigs. Mucosal TNF did not differ among treatments (peroxidation, main effect $P=0.739$ ).

\section{Discussion}

This study involved incremental increases in peroxidation (rather than a static dose) of soyabean oil on the growth performance of pigs and on selected variables related to structure 
Table 4. Effects of peroxidised dietary soyabean oil on oxidative stress, antioxidant activity, TNFa and villus morphology in the jejunum of nursery pigs (Least squares means with their standard errors)

\begin{tabular}{|c|c|c|c|c|c|c|c|c|c|c|}
\hline \multirow[b]{2}{*}{ Items } & \multirow[b]{2}{*}{ Control† } & \multicolumn{4}{|c|}{ Days of peroxidative exposure* } & \multirow[b]{2}{*}{ SEM } & \multicolumn{4}{|c|}{$P$} \\
\hline & & 0 & 6 & 9 & 12 & & Control $v$. oil added $\ddagger$ & Peroxidation§ & Linear & Quadratic \\
\hline MDA ( $\mu \mathrm{mol} / \mathrm{g}$ protein) & $35^{\mathrm{b}}$ & $45^{\mathrm{a}, \mathrm{b}}$ & $54^{\mathrm{a}}$ & $59^{\mathrm{a}}$ & $37^{\mathrm{a}, \mathrm{b}}$ & $6 \cdot 4$ & 0.273 & 0.131 & 0.762 & 0.035 \\
\hline TAC ( $\mu$ mol CRE/g protein) & $52^{b}$ & $57^{\mathrm{a}, \mathrm{b}}$ & $59^{\mathrm{a}}$ & $55^{\mathrm{a}, \mathrm{b}}$ & $52^{b}$ & $2 \cdot 7$ & 0.155 & 0.059 & 0.044 & 0.101 \\
\hline TNF (pg/mg protein) & 8 & 12 & 9 & 11 & 17 & 4.0 & 0.546 & 0.739 & 0.503 & 0.317 \\
\hline \multicolumn{11}{|l|}{ Villus morphology $(\mu \mathrm{m})$} \\
\hline Villus height & $529^{b, c}$ & $504^{\mathrm{c}}$ & $531^{\mathrm{b}}$ & $572^{\mathrm{a}}$ & $563^{\mathrm{a}}$ & $10 \cdot 0$ & 0.077 & $<0.001$ & $<0.001$ & 0.479 \\
\hline Villus width & $139^{b}$ & $147^{\mathrm{a}}$ & $143^{a, b}$ & $141^{a, b}$ & $135^{\mathrm{b}}$ & $3 \cdot 0$ & 0.025 & 0.019 & 0.002 & 0.560 \\
\hline Crypt depth & $167^{\mathrm{C}}$ & $168^{\mathrm{c}}$ & $182^{\mathrm{a}, \mathrm{b}}$ & $187^{a}$ & $177^{\mathrm{b}, \mathrm{c}}$ & 4.0 & 0.761 & 0.004 & 0.028 & 0.005 \\
\hline Villus area\| & 0.25 & 0.25 & 0.25 & 0.26 & 0.25 & 0.01 & 0.659 & 0.851 & 0.735 & 0.796 \\
\hline Villus height:crypt depth & $3 \cdot 17^{\mathrm{a}}$ & $2.99^{\mathrm{b}}$ & $2 \cdot 91^{\mathrm{b}}$ & $3.06^{a, b}$ & $3.19^{\mathrm{a}}$ & 0.08 & 0.159 & 0.035 & 0.079 & 0.022 \\
\hline
\end{tabular}

MDA, malondialdehyde; TAC, total antioxidant capacity; CRE, Cu-reducing equivalents.

a,b,c Least squares mean values within a row with unlike superscript letters were significantly different $(P \leq 0.05)$

* Soyabean oil added to diets was exposed to peroxidation for $0,6,9$ and $12 \mathrm{~d}$ by exposing to heat $\left(80^{\circ} \mathrm{C}\right)$ and constant oxygen flow ( 1 litre/min) and fed to pigs for $35 \mathrm{~d}$.

† Control diet was not supplemented with soyabean oil.

$\ddagger P$ value corresponding to the comparison of control diet with $0 \mathrm{~d}$ peroxidised lipid-added diet.

$\S$ The main effect of lipid peroxidation was tested. Orthogonal contrasts were performed to evaluate linear and quadratic effects of lipid peroxidation.

II The surface area $\left(\mu \mathrm{m}^{2}\right)$ of the villus was calculated using the formula for the surface area of a cylinder and subtracting the area of the base of the villus.

and function of the small intestine. Peroxidation of soyabean oil was induced by heating at $80^{\circ} \mathrm{C}$ with constant oxygen flow, similar to DeRouchey et $a l^{(8)}$. Using this approach, we successfully obtained increasing degrees (or dose) of peroxidation. Therefore, we speculate that the responses observed in this study were caused directly by increasing the degree of peroxidation.

During lipid peroxidation, many reactions occur that result in a large number of unstable compounds (hydroperoxides, aldehydes, alcohols, conjugated dienes, polymers and so on $)^{(6)}$. The degree of lipid peroxidation is very difficult to characterise because these unstable compounds decompose as peroxidation progresses, and their concentrations in lipids depend on the conditions of peroxidation (i.e. heating at low or high temperature $)^{(26)}$. A reliable characterisation must include the quantification of different peroxidation products including primary (i.e. hydroperoxides) and secondary (i.e. aldehydes) products $^{(27)}$. We estimated the degree of peroxidation by measuring peroxide, $p$-anisidine and MDA values. Peroxide value estimates the hydroperoxide concentration, which reflects the primary products of peroxidation. Because hydroperoxides are unstable and can decompose into secondary products (i.e. aldehydes, ketones, alcohols and so on), the peroxide value by itself may underestimate the true degree of peroxidation $^{(28)}$. To better estimate the concentrations of secondary products of peroxidation such as aldehydes, we measured MDA and the $p$-anisidine value of the oil. In our study, soyabean oil heated for different lengths of time had increased hydroperoxide concentrations until d 9 of peroxidation and remained relatively constant at $\mathrm{d} 12$; however, $p$-anisidine and MDA concentrations continued to increase as peroxidative exposure progressed. The increasing degrees or dose of peroxidation of soyabean oil reported in this study have implications in human and animal nutrition because these degrees are comparable to those reported by Sebastian et al. ${ }^{(5)}$ for 'in-use' (peroxide values up to $48 \mathrm{mEq} \mathrm{O}_{2} / \mathrm{kg}$ and $p$-anisidine values up to 41 ) and 'discarded' (peroxide values up to $248 \mathrm{mEq} \mathrm{O} / \mathrm{kg}$ and p-anisidine values up to 57) frying oils from twenty restaurants in Canada. In addition, these researchers showed that about $50 \%$ of frying oils from restaurants contained $p$-anisidine values $>25$, which correspond to the soyabean oil exposed to peroxidation for more than $9 \mathrm{~d}$ in our study.

Addition of peroxidised soyabean oil to nursery diets had detrimental effects on animal performance, especially after feeding pigs for long periods $(>14 \mathrm{~d}$ ). In agreement with previous reports $^{(8,29)}$, we observed a progressive reduction in feed intake for pigs fed soyabean oil exposed to peroxidation. Products of peroxidation may affect the palatability of the diet, which could result in reduced feed intake ${ }^{(29)}$. Consequently, dietary soyabean oil exposed to peroxidation negatively affected BW gain of pigs. The observed $9 \%$ reduction in BW gain (when comparing 0 and $12 \mathrm{~d}$ of peroxidation) was largely the result of reduced feed intake ( $7 \%$ reduction when comparing 0 and $12 \mathrm{~d}$ ), but it could also be related to enterocyte dysfunction, oxidative stress and so on. Kanazawa et al. ${ }^{(7)}$ concluded that lipid peroxidation impaired the functionality of the intestine as indicated by decreased enzyme activity (sucrase, maltase and alkaline phosphatase) in the jejunum and ileum after oral administration of products of peroxidation of linoleic acid to rats. In the current study, the improvement in daily BW gain because of the addition of unexposed soyabean oil when compared with the control diet was progressively diminished as the degree of peroxidation increased. Our results are in agreement with those presented by DeRouchey et al. ${ }^{(8)}$, who reported a linear reduction in pig performance when choice white grease (primarily containing lard) was exposed to peroxidation for increasing lengths of time (0, 5, 7, 9 and $11 \mathrm{~d})$. Similar to previous reports ${ }^{(8,29)}$, negative effects on animal performance were more evident when animals were fed dietary treatments for longer periods of time ( $>14 \mathrm{~d})$.

We used mannitol (sugar alcohol with a molecular mass of $182 \mathrm{Da}$ ) and D-xylose (monosaccharide with a molecular mass of $150 \mathrm{Da}$ ) as markers to assess the absorptive capacity of the small intestine because these sugars can be actively absorbed 
across the brush-border membrane by a carrier-mediated process or by paracellular diffusion ${ }^{(30-33)}$. These sugars have been used extensively as indicators of malabsorption in birds ${ }^{(23,34)}$ and to test intestinal barrier function in multiple species $^{(35-37)}$. In the present study, we observed that the capacity to absorb mannitol and D-xylose tended to progressively reduce as peroxide dose increased. These results are consistent with the gradual reduction in the digestion of fat and gross energy and with the modified structure of the small intestine. Apparent fat digestibility is defined as the net disappearance of ingested dietary fat from the digestive tract and reflects the enzymatic hydrolysis, micelle formation and absorption of fat from the gastrointestinal lumen. In the present study, increasing dose of lipid peroxidation progressively reduced the apparent fat digestibility. Our observations are in agreement with those presented by DeRouchey et al. ${ }^{(8)}$, who reported a reduction (in a quadratic manner) in the digestibility of nutrients when pigs were fed lipids exposed to peroxidation. Our findings on the intestinal absorptive capacity and apparent digestibility of fat and gross energy suggest that dietary soyabean oil exposed to peroxidation impaired intestinal function and that these detrimental effects are accentuated by increasing degree and duration of peroxidative challenge.

The intestinal cell transition to proliferative, growth arrest or apoptotic states is thought to be governed by the biological redox balance of cellular signalling events ${ }^{(38-44)}$. Any disturbance in the redox balance results in cellular oxidative stress and cell transition status ${ }^{(45)}$. Tian et al. ${ }^{(46)}$ provided evidence that oxidised colonic mucosal redox status promoted cell growth and proliferation. The researchers induced alterations in the redox balance of colonic mucosal in rats by inhibiting the enzyme GSH/GSSG. In our study, the changes in villus structure and villus height:crypt depth ratios suggest that lipid peroxidation accentuated enterocyte proliferation as a result of oxidative stress in the small intestine of pigs. This contention was supported by the increased concentrations of MDA and progressive reduction of antioxidant capacity in the intestinal mucosa of pigs. Other studies have demonstrated that dietary lipid peroxidation products can induce cellular oxidative stress $^{(3,11,13)}$. However, to our knowledge, this is the first study to demonstrate that increasing dose of lipid peroxidation products progressively disrupted the redox environment in the intestine and proposed this induction of oxidative stress as the mechanism for the impairment of the structure and function of the small intestine.

Strong oxidative stress, as a result of dietary peroxidative challenge, could disrupt cell integrity and activate proinflammatory transcription factors ${ }^{(2)}$. We explored the potential effects of lipid peroxidation on intestinal inflammation by measuring mucosal concentrations of TNF and did not observe any significant effects. Our results are in agreement with those presented by Ringseis ${ }^{(11)}$, who demonstrated that dietary peroxidised lipids induced oxidative stress in pigs, without causing inflammation. In contrast, Varady et al. ${ }^{(12)}$ administered orally by gavage peroxidised lipids to female mice and concluded that ingestion of peroxidised lipids activated proinflammatory transcription factors. It is plausible that the lack of inflammatory response to lipid peroxidation was because of the limited analysis performed in our study and that other inflammatory markers, including lipid-mediated markers (i.e. PG and leukotrienes), could be elevated ${ }^{(47,48)}$. Future studies that investigate TNF and other inflammatory mediators are needed to clarify the extent and duration of peroxidative challenge that may cause intestinal inflammatory responses in vivo.

In conclusion, lipid peroxidation reduced animal growth, reduced digestion and absorption of nutrients and modified villus morphology of the small intestine. We infer that disruption of the redox environment in the intestine is the mechanism by which the structure and function of the small intestine were impaired. Detrimental effects of lipid peroxidation were progressively accentuated by a dose-related increase in lipid peroxidation products. In this context, we suggest that the biological response to lipid peroxidation, to the degree tested in the present study, is progressive so that the extent to which measures are affected must be stated in relation to the dose of peroxidation products. This principle should be considered in future studies pertaining to the effects of significant lipid peroxidation, which could include viability and medical treatment.

\section{Acknowledgements}

The present study was supported in part by the North Carolina Pork Council, Raleigh, NC. The North Carolina Pork Council had no role in the design, analysis or writing of this article.

D. S. R. and E. v. H. designed the research study. D. S. R. conducted the study, analysed data and wrote the paper. J. O., A. J. M., R. D. B. and E. v. H. were involved in portrayal of the data, interpretation of the analysis and they conducted a critical review of the manuscript. All authors read and approved the final manuscript.

The authors declare that there are no conflicts of interest.

\section{References}

1. Grisham MB \& Granger DN (1988) Neutrophil-mediated mucosal injury: role of reactive oxygen metabolites. Dig Dis Sci 33, 6-15.

2. Bernotti S, Seidman E, Sinnett D, et al. (2003) Inflammatory reaction without endogenous antioxidant response in Caco-2 cells exposed to iron/ascorbate-mediated lipid peroxidation. Am J Physiol Gastrointest Liver Physiol 285, G898-G906.

3. Tsunada S, Iwakiri R, Fujimoto K, et al. (2003) Chronic exposure to subtoxic levels of peroxidized lipids suppresses mucosal cell turnover in rat small intestine and reversal by glutathione. Dig Dis Sci 48, 210-222.

4. Frankel EN (1984) Occurrence of cyclic fatty acid monomers in frying oils used for fast foods. J Am Oil Chem Soc 61, 87-90.

5. Sebastian A, Ghazani SM \& Marangoni AG (2014) Quality and safety of frying oils used in restaurants. Food Res Int 64, 420-423.

6. Kimura T, Iida K \& Takei Y (1984) Mechanisms of adverse effect of air-oxidized soybean oil-feeding in rats. J Nutr Sci Vitaminol (Tokyo) 30, 125-133.

7. Kanazawa K, Ashida H, Minamoto S, et al. (1988) The effects of orally administered linoleic acid and its autoxidation products on intestinal mucosa in rat. J Nutr Sci Vitaminol (Tokyo) 34, 363-373.

8. DeRouchey JM, Hancock JD, Hines RH, et al. (2004) Effects of rancidity and free fatty acids in choice white grease on growth 
performance and nutrient digestibility in weanling pigs. J Anim Sci 82, 2937-2944.

9. Dibner JJ, Atwell CA, Kitchell ML, et al. (1996) Feeding of oxidized fats to broilers and swine: effects on enterocyte turnover, hepatocyte proliferation and the gut associated lymphoid tissue. Anim Feed Sci Technol 62, 1-13.

10. Gotoh Y, Noda T, Iwakiri R, et al. (2002) Lipid peroxideinduced redox imbalance differentially mediates CaCo-2 cell proliferation and growth arrest. Cell Prolif 35, 221-235.

11. Ringseis R, Piwek N \& Eder K (2007) Oxidized fat induces oxidative stress but has no effect on NF-kB-mediated proinflammatory gene transcription in porcine intestinal epithelial cells. Inflamm Res 56, 118-125.

12. Varady J, Eder K \& Ringseis R (2011) Dietary oxidized fat activates the oxidative stress-responsive transcription factors $\mathrm{NF}-\mathrm{\kappa B}$ and Nrf2 in intestinal mucosa of mice. Eur J Nutr $\mathbf{5 0}$, 601-609.

13. Liu JF \& Lee YW (1998) Vitamin C supplementation restores the impaired vitamin $\mathrm{E}$ status of guinea pigs fed oxidized frying oil. J Nutr 128, 116-122.

14. Aw TY (1999) Molecular and cellular responses to oxidative stress and changes in oxidation-reduction imbalance in the intestine. Am J Clin Nutr 70, 557-565.

15. Liu P, Chen C, Kerr BJ, et al. (2014) Influence of thermally oxidized vegetable oils and animals fats on intestinal barrier function and immune variables in young pigs. J Anim Sci $\mathbf{9 2}$, 2980-2986.

16. Liu P, Chen C, Kerr BJ, et al. (2014) Influence of thermally oxidized vegetable oils and animals fats on growth performance, liver gene expression, and liver and serum cholesterol and triglycerides in young pigs. J Anim Sci 92 , 2960-2970.

17. National Research Council (1998) Nutrient Requirements of Swine, 10th ed. Washington, DC: National Academies Press.

18. Association of Official Analytical Chemists (1990) Official Methods of Analysis, 15th ed. Arlington, VA: AOAC.

19. American Oil Chemists' Society (1998) Official Methods and Recommended Practices of the American Oil Chemists Society, 5th ed. Champaign, IL: AOCS.

20. Myers WD, Ludden PA, Nayigihugu V, et al. (2004) Technical note: a procedure for the preparation and quantitative analysis of samples for titanium dioxide. J Anim Sci 82, 179-183.

21. American Oil Chemists' Society (2005) Official Procedures of the American Oil Chemists' Society, Approved Procedure Am 5-04, Rapid Determination of Oil/Fat Utilizing High Temperature Solvent Extraction. Urbana, IL: AOCS.

22. Adeola O (2001) Digestion and balance techniques in pigs. In Swine Nutrition, 2nd ed. pp. 903-916 [AJ Lewis and L Southern, editors]. New York: CRC Press.

23. Doerfler RE, Cain LD, Edens FW, et al. (2000) D-Xylose absorption as a measurement of malabsorption in poult enteritis and mortality syndrome. Poult Sci 79, 656-660.

24. Jahnel JB, Ilieva P \& Frimmel FH (1998) HPAE-PAD: a sensitive method for the determination of carbohydrates. Fresenius J Anal Chem 360, 827-829.

25. Moeser AJ, Nighot PK, Ryan KA, et al. (2006) Prostaglandinmediated inhibition of $\mathrm{Na}+\mathrm{H}+$ exchanger isoform 2 stimulates recovery of barrier function in ischemia-injured intestine. Am J Physiol Gastrointest Liver Physiol 291, G885-G894.

26. Chang SS, Peterson RJ \& Ho CT (1978) Chemical reactions involved in the deep-fat frying of foods. J Am Oil Chem Soc 55, 718-727.

27. Liu P, Kerr BJ, Chen C, et al. (2014) Methods to create thermallyoxidized lipids and comparison of analytical procedures to characterize peroxidation. J Anim Sci 92, 2950-2959.
28. Ross CF \& Smith DM (2006) Use of volatiles as indicators of lipid oxidation in muscle foods. Compr Rev Food Sci Food Saf $\mathbf{5}, 18-25$.

29. Nwanguma BC, Achebe AC, Ezeanyika LUS, et al. (1999) Toxicity of oxidized fats II: tissue levels of lipid peroxides in rats fed a thermally oxidized corn oil diet. Food Chem Toxicol 37, 413-416

30. Bjarnason I, Macpherson A \& Hollander D (1995) Intestinal permeability: an overview. Gastroenterology $\mathbf{1 0 8}$, 1566-1581.

31. Uil JJ, van Elburg RM, van Overbeek FM, et al. (1996) Clinical implications of the sugar absorption test: intestinal permeability test to assess mucosal barrier function. Scand $J$ Gastroenterol, Suppl. 223, 70-78.

32. Craig RM \& Ehrenpreis ED (1999) D-Xylose testing. J Clin Gastroenterol 29, 143-150.

33. Johnston SD, Smye M \& Watson RP (2001) Intestinal permeability tests in coeliac disease. Clin Lab 47, 143-150.

34. Goodwin MA, Latimer KS, Nersessian BN, et al. (1984) Quantitation of intestinal D-xylose absorption in normal and reovirus-inoculated turkeys. Avian Dis 28, 959-967.

35. Moeser AJ, Ryan KA, Nighot PK, et al. (2007) Gastrointestinal dysfunction induced by early weaning is attenuated by delayed weaning and mast cell blockade in pigs. Am J Physiol Gastrointest Liver Physiol 293, G413-G421.

36. Boudry G, Péron V, Huërou-Luron I, et al. (2004) Weaning induces both transient and long-lasting modifications of absorptive, secretory, and barrier properties of piglet intestine. J Nutr 134, 2256-2262.

37. Cabrera RA, Usry JL, Arellano C, et al. (2013) Effects of creep feeding and supplemental glutamine or glutamine plus glutamate (Aminogut) on pre- and post-weaning growth performance and intestinal health of piglets. J Anim Sci Biotechnol 4, 29.

38. Kanazawa K \& Ashida H (1998) Dietary hydroperoxides of linoleic acid decompose to aldehydes in stomach before being absorbed into the body. Biochim Biophys Acta 1393, 349-361.

39. Rao GN, Glasgow WC, Eling TE, et al. (1996) Role of hydroperoxy eicosatetraenoic acids in oxidative stressinduced activating protein 1 (AP-1) activity. $J$ Biol Chem 271, 27760-27764.

40. Sandstrom PA, Pardi D, Tebbey PW, et al. (1995) Lipid hydroperoxide-induced apoptosis: lack of inhibition by Bcl-2 over-expression. FEBS Lett 365, 66-70.

41. Aw TY (2005) Intestinal glutathione: determinant of mucosal peroxide transport, metabolism, and oxidative susceptibility. Toxicol Appl Pharmacol 204, 320-328.

42. Circu ML \& Aw TY (2012) Intestinal redox biology and oxidative stress. Semin Cell Dev Biol 23, 729-737.

43. Noda T, Iwakiri R, Fujimoto K, et al. (2001) Induction of mild intracellular redox imbalance inhibits proliferation of CaCo-2 cells. FASEB J 15, 2131-2139.

44. Aw TY (2003) Cellular redox: a modulator of intestinal epithelial cell proliferation. News Physiol Sci 18, 201-204.

45. Jones DP (2006) Redefining oxidative stress. Antioxid Redox Signal 8, 1865-1879.

46. Tian J, Washizawa N, Gu LH, et al. (2007) Stimulation of colonic mucosal growth associated with oxidized redox status in rats. Am J Physiol Regul Integr Comp Physiol 292, R1081-R1091.

47. Basu S (2004) Isoprostanes: novel bioactive products of lipid peroxidation. Free Radic Res 38, 105-122.

48. Montuschi P, Barnes PJ \& Roberts LJ (2004) Isoprostanes: markers and mediators of oxidative stress. FASEB $J \mathbf{1 8}$, $1791-1800$ 